\title{
A Linguo-Cultural Approach to the Integration of Hip-hop Culture with Chinese Culture---Taking Rap Music as an Example
}

\author{
Zhanghong Xu, Xiaolin Liu \\ Email address: \\ 1458975262@qq.com (Zhanghong Xu), 1617890549@qq.com (Xiaolin Liu)
}

Department of English for Law, School of English for International Business, Guangdong University of Foreign Studies, Guangzhou, China

To cite this article:

Zhanghong Xu, Xiaolin Liu. A Linguo-Cultural Approach to the Integration of Hip-hop Culture with Chinese Culture---Taking Rap Music as an Example. International Journal of Literature and Arts. Vol. 7, No. 6, 2019, pp. 165-171. doi: 10.11648/j.ijla.20190706.16

Received: November 8, 2019; Accepted: November 27, 2019; Published: December 6, 2019

\begin{abstract}
Cultural integration is an inevitable trend of the development of cultural globalization. With the rapid development of mass media and frequent communication among people from various cultural backgrounds, hip-hop culture with its exotic musical form and its unique themes, interacts with other cultures by confronting, adapting and integrating different worldviews and lifestyles. This paper attempts to explore how the hip-hop culture (rap music in particular), which originated from American-African people, realized cultural integration in China, and what manifestations this integration had. Drawing on Cultural Acculturation Theory and making detailed textual analysis, we found that the integration of rap music with Chinese culture takes three approaches, i.e., transmission, localization and adaptation, and transformation. The integration mainly manifests itself in four aspects: form of lyrics, content of lyrics, language use of rap and dress-up of rappers, all of which are illustrated with concrete examples. Further discussions reveal that hip-hop culture is largely accepted by the majority of Chinese teenagers, for it is constantly mitigating and even discarding the violent and negative characteristics during the integration with China's mainstream values. This study is believed to shed light on the nature of cultural integration, musical integration in particular, and to convince people that taking advantage of hip-hop culture critically to inject new vitality into Chinese traditional culture will promote the further development of Chinese culture in new era.
\end{abstract}

Keywords: Cultural Integration, Hip-Hop Culture, Rap Music

\section{Introduction}

Cultural integration is an inevitable trend of the development of cultural globalization [1]. With the rapid development of mass media and frequent communication among people from various cultural backgrounds, hip-hop culture, which originated from American-African people, interacts with other cultures and constantly integrates with local culture [2]. Therefore, different countries have distinctive hip-hop culture with strong national character now [1].

As one of the most popular global youth cultures, hip-hop culture is a subculture and art movement developed in the Bronx in New York City during the late 1970s, and has become popular all over the world since the end of last century [26]. The development of hip-hop culture reflects the trend and characteristics of the combination of globalization and localization---"glo-calization" as Roberson (1994) termed [3].
In 1970s, serious social problems arose among Black Americans, such as dropping out of school and losing their jobs. According to the social statistics, the unemployment rate of black youth is twice the white youth, and the murder rate is nine times higher than the White [2]. A man called Afrika Bambaataa wanted to end the Bronx street gang violence at that time, so he organized a large block party with another DJ Kool Herk to help young people to vent emotions and relieve stress through music and dance. This street music and dance spread quickly through many immigrants' communities in New York City and was gradually accepted by the American society.

In the late $1980 \mathrm{~s}$, due to globalization and the waves of de-industrialization which swept across the world, high unemployment plagued many people, especially the urban youth of the low-income groups. Thus, the hip-hop culture provided a way to express personal thought and an approach to communication with the mainstream society. In The Rise 
of Islamic Rap, Mandaville found that hip hop has become a form of protest against the mainstream culture. For example, European immigrant youth widely use the hip-hop music and hip-hop dance to show their sense of alienation, the racism they felt, and the repressed political consciousness [2]. With the continuous progress of human civilization and the rapid development of the global economy, the common problems faced by mankind have become the theme of hip-hop music, such as anti-war, environmental protection and other global issues. At the same time, the hip-hop culture is more inclined to entertain people by displaying their innovation of skills rather than the violent rebellion against the mainstream culture under the commercial packaging.

The success of a domestic show The Rap of China brought hip-hop culture into a public sphere in China in 2017. However, the PGone Event (as a Chinese rapper, PGone was exposed to have a love affair with a married Chinese actress) and some songs from well-known rappers with indecent language or wrong values sparked a heated debate on hip-hop culture, which led to a generally negative impression on common people. After that, there was nearly no great rap music in China, and many rappers disappeared from the public. This unexpected change bewilders many scholars and stirs up people's interest in the underlying causes of the shrinking existence and their curiosity on the future development of hip-hop culture. Thus, the purpose of this study is to explain how hip-hop culture---taking rap music as an example---realizes cultural integration in China and what manifestations it has. Finally, we will attempt to discuss how this kind of cultural integration should be appropriately accepted in spite of many negative events.

The paper is organized as follows. Section 1 introduces the research background, motivation and purpose. Section 2 will review the previous study on hip-hop culture. Research methodology will be introduced in section 3, which includes the theoretical framework of cultural integration and research questions and method. The main part of this paper, Section 4 will then focus specifically on the analysis of integration approaches and manifestations of integration between hip-hop culture (taking rap music as example) and Chinese culture. The conclusions will be presented, and limitations and suggestions pointed out in section 5 .

\section{Literature Review}

The integration of hip-hop culture has interested many scholars from various fields ever since its advent, particularly in the 21st century. Philip et al (2007) found that hip-hop has become an attraction for tourists and it is a component of cultural tourism [4]. Consequently, hip-hop can be an important marketing and management asset for tourism by exploring the interrelations between culture, tourists and attractions in specific settings. Besides, an increasing number of scholars explored the hip-hop changes and expressions in different countries or regions. For example, Jaspal and Ethiraj (2016) studied the formal and informal hip-hop pedagogies in India, and concluded that the hip-hop pedagogues need to reposition their role and practices creatively in international context [5]. Matt (2014) analyzed the relationship of orthography, morphology and phonology in English -ed suffix, which is adapted to the German hip hop and its nativization in it [6]. Athena (2013) investigated how hip hop became a legitimated authentic musical form through local and trans-local authentication in limited specific cultural production field by hip-hop practitioners in Greece [7], etc. Almost all the relevant studies have emphasized the localization of hip-hop culture after entering a new environment. In addition, some scholars explored the social problems in hip-hop community. Ashish et al (2017), the first team, explored the lyrical themes related to abortion and family planning in 101 songs, which derived from total 6577 songs from 1990 to 2015 by Genius. They introduced a unique perspective to know about the thought on abortion of a specific group, the black community. It turned out that these songs are full of negative connotations, such as the use of abortion to show men's charm and male pressure for women to seek abortion, etc. [8]. Some scholars found that hip-hop peer crowd was more likely use tobacco and they could be a promising group to be educated [9].

China, a country where the term "hip-hop culture" is almost never heard of before 21 century, now has become the target to be explored. Katy (2009) found that the Chinese youth who are in the business of hip-hop face many hurdles that range from state repression, self-censorship, and the desire to create a community of resistance to the authoritarian attitudes on specific occasions [10]. Hip-hop still faces numerous challenges in China. Barrett (2012) took Agha's Emblematic Figures of Identity as a framework to explore the processes of identity formation between local and foreign artists mediated by language in the Chinese hip-hop community through various methods, including interviews, lyric analysis and observations (eg. recording-studio and live performance observation) [11]. The final findings were similar to what Omoniyi (2009) identified as the case in Nigerian hip-hop that China is to create hip-hop rooted in local characteristics [12]. In China, several scholars analyzed the localization of Chinese hip-hop in terms of lyrics and content. Ping (2014) found that local-practicality, inter-dynamic and contradictory developments are three characteristics of youth cultural globalization [13]. Ruiying (2017) pointed out that the localization of rap music in The Rap of China and offered several suggestions on further localization of hip hop in China [14].

Beyond that, some scholars discussed the pedagogical significance of hip hop culture. The pedagogical design of street dance, one representative of hip-hop culture, was studied by Hong (2019) [15] and Li \& Guan (2019) [16]. Some other researchers investigated the influence that hip-hop music exerted on Chinese youth and the values it expressed as well as how to guide them through hip-hop music $[17,18]$. Through questionnaires, they found that many young people did not know about the racial issues and civil rights issues behind hip-hop culture and had a superficial understanding of the real hip-hop spirit, so the majority of them only imitated the 
"COOL" appearance. Thus, government, school and parents are all expected to supervise and guide the development and localization of hip-hop culture in China so as to improve the cultural environment for the young.

By largely employing observation method, the majority of research on hip-hop culture focus on three topics: (1) identity construction in hip-hop culture in various cultural backgrounds, (2) challenges and conflicts of hip-hop culture in new environments, and (3) the features of localization of hip-hop culture in terms of rap music and street dance in certain areas [19, 20, 21]. However, most of the current research seems to be somewhat subjective or impressionistic, unable to present an objective picture of hip-hop acculturation. Therefore, this paper attempts to explore hip-hop culture from the perspectives of linguistics and cross-cultural communication, specifically, to adopt cultural integration strategy in Cultural Acculturation Theory to explain the integrating process and present the manifestation of integration with specific examples.

\section{Methodology}

\subsection{Theoretical Framework}

Cultural Integration, one of fourfold model of Cultural Acculturation strategies, which refers to a complex process whereby different cultures with distinctive features integrate each other as a whole through communication, mutual absorption and learning, is often synonymous with pluralism. One outcome is that of being integrated completely by dominant culture, just as assimilation; the other outcome is that of learning from each other but still maintaining its own features and even creating a new culture [1]. There are three processes of cultural integration: contacting through dissemination, adapting and localizing through conflicts or peaceful selection, final integration [1], and it takes three corresponding approaches: cultural transmission, cultural adaptation and localization, and cultural transformation. Cultural Acculturation is not separate but an interdependent and dynamic process [22]. The following figure is adapted from the above-mentioned theory.

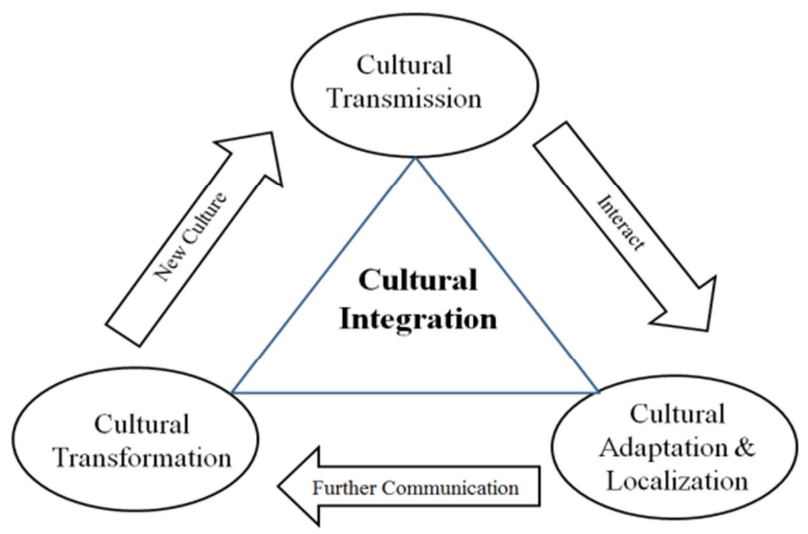

Figure 1. Dynamic processes/approaches of Cultural Integration. also described as naturally "cultural dialogue", which refers to the tendency of cultural transmission and interaction. In reality, one aspect of "cultural dialogue" is the development of society, and technology has cleared the barriers for the flow of different cultures---broken time and space such as sound recorder, video, television, etc. The other aspect is the interaction between people with different cultural environment as well as frequent trade and communication as the main body of cultural transmission. Therefore, the natural flow and transmission of culture has become the most universal and basic approach of cultural integration.

The second approach of cultural integration is cultural adaptation and localization. Cultural adaptation refers to the process whereby the continuous direct contact made by people from different cultural groups leads to the change of the original type of one or both parties [23]. That is the process a group undergoes to integrate into a new culture and feels comfortable within it. During the adaptive process, original culture may absorb local culture to adapt local environment. This method is called localization, which means that original cultural quintessence is extracted and then is combined with the local features even to create another new culture. Cultural Adaptation and Localization require people to either actively or passively learn from others and act as a kind of "adjustment" in order to "survive" in a new cultural environment. The transformation of culture is the renewal of culture, which indicates not only the furthest approach but also the inevitable outcome of cultural integration.

Cultural integration is neither complete uniformity nor simple replacement between foreign culture and native culture. Cultural integration is defined herein as a form of cultural innovation, a continuous adjustment and absorption process through constant conflicts or selections and even by absorbing the third-party culture to restructure and update culture based on local culture. It is an inevitable trend of the development of cultural globalization as Robertson (1994) observed [3].

\subsection{Research Objectives}

The paper aims to explore the processes of the hip-hop cultural integration in China, and identify the manifestations of this integration. Specifically, two research questions are to be addressed: How does hip-hop culture, which is rooted in U.S. African-American culture, integrate with Chinese culture? What are the manifestations of the hip-hop cultural integration in China?

In next section, we will explain how the integration of hip-hop culture with Chinese culture based on cultural integration model, and then present the manifestations of integration with concrete examples. Finally, further discussions on the current situation of Chinese hip-hop will be carried out so as to help people gain a better understanding of hip-hop culture.

The first approach is cultural exchange and transmission, 


\section{Analysis of the Integration of Hip-hop Culture with Chinese Culture}

\subsection{Transmission of Hip-hop Culture: Breaking the Time and Space Boundaries}

The development of modern science and technology can bring together the advantages of various mass media. Radio and television use modern electronic technology to transmit hip-hop culture. The computerization of information delivery and newspaper production technology has simplified the editing, layout, printing and distribution process, breaking the limitation of time and space so as to spread hip-hop culture rapidly and extensively. For instance, hip-hop rap music could be recorded in tape or video, could be spread through TV program, websites, etc. In this way, people from all over the world have access to hip-hop culture in any place and at any time.

In addition, hip-hoppers from different countries can communicate and interact through a series of programs, competitions and festivals. Similar to the world's most authoritative hip-hop street dance competition--- JUSTE DEBOUT that invites dancers from all over the world to compete with each other, Australian International Agency Rap Competition also provides a broad platform for rappers to interact and learn from each other, etc. In China, The Rap of China competition program provides a good platform for the majority of rappers to communicate with each other. This webcast program has made more and more people learn about hip-hop culture. The success of the program opened the door to the development of hip-hop culture in China and gradually brought this underground subculture to the stage. There is no doubt that cultural communication must be committed to the principle of equity in interaction.

\subsection{Adaptation and Localization of Hip-Hop Culture in China---Based on Rap Music}

\subsubsection{Adaptation and Localization in the Form of Lyrics}

Foreign hip-hop rap music must adapt itself to Chinese singing style and form to make it acceptable to local people, that is, to "survive" in new environment. Thus, in the form of lyrics, Chinese rap is not simple translation of foreign rap from English into Chinese, but a recreation of lyrics and style. Chinese rap music pays special emphasis on ryhme. Here, the author adopted Xing Fuyi's (2006) classification of rhyme: Rhyming Feet are several same rhyming syllables that end a line of sentence in verse. Rhyme refers to the same rhyming syllables that appear repeatedly and regularly at the end of the sentence [24]. The same rhyming syllables here include the same syllables as the entire vowel and the syllables with the same or similar main vowel in diphthong and Tail Vowel. Look at the following examples.

Example 1:

Wo ganxie wodeta taduiwo fuchude ai

(Thanks for her love for me.)

Ganxieta duiwodezhaogu meiwande fan cai

(Thank her for taking care of me and the dinner for me every night.)

Ganxieta duiwodezhichi lijieyu qi dai

(Thanks for her understanding, support and expectation.)

Shita rangwo ganjuewennuan youjiade cun zai

(It is she who makes me feel warm and at home.)

From Thank of Dragonking [25]

It is found that the clip lyrics of the whole rap are mainly in ai rhyming feet. In prosody, ai rhyming feet belongs to Kaikouhu rhyming feet according to the articulation of pronunciation. Xing (1991) thought that Kaikouhu articulation is very sonorous, magnificent and fluctuating, which is easy to express and memorize [24]. Kaikouhu rhyming feet are also beneficial to the chants for short breath so as to guarantee the quality of timbre and melody. Besides, ai cai dai zai four words in clip of this rap are all fall tone, which make the whole clip more rhythmic.

Example 2:

Haizimen yanzhongdexiwang shishenme xing zhuang

(What shape of the hope is in children's eyes?)

Shifou xinglai youmianbaogenzaocan zai hewan nong tang

(Do they wake up with bread and breakfast, and then have another bowl of hot thick soup?)

Nongfumen shaohui tudi gen cunzhuang zhongyu naqi qiang

(The farmers burned down the land and the village and finally picked up their guns.)

Taque manmanxiguan fangqile di kang

(But he got accustomed, and gave up resistance.)

From Wounds of war of Jay Chou [25]

The majority of lyrics of this rap are in ang rhyming feet. The excerpts of the rap are entirely in ang rhyming feet, which are sonorous. In prosody, the final syllables of each sentence, which are all sonorous, are called sonorants. These sonorants can string each lyric into a whole reciprocating part in order to express strong feelings. When the lyrics are too long, kaikouhu rhyming feet ang can help rappers take a short breath when the air is weakened, thus, ensuring the quality of the timbre and melody.

Of course, other kinds of rhymes and the patterns of level and oblique tones all appear in the rap lyrics, such as Variable rhyme, Embraced rhyme, etc. The two examples mentioned above are given to explain the Chinese rap lyrics form. In short, rhyme can make the rap more magnificent, rhythmic and likely to be memorized.

\subsubsection{Adaptation and Localization in the Content of Lyrics}

The content of lyrics in this paper is limited to two dimensions: diction and values conveyed. Unlike the American rap lyrics, which are characterized by political and religious words, the Chinese rap lyrics mainly derive their way of expression from common buzzwords and daily expressions. Some dirty words frequently appear in the Chinese rap lyrics, which pay much attention to local society and the inner voice of the people at the bottom of society, such as drawing on the local culture, denouncing the NEET (Not currently engaged in Employment, Education and Training), etc. Consequently, the sharpness of the social 
criticism and politics greatly abates. Although Chinese rap lyrics are not free from dirty words, they are less used in the Chinese rap lyrics than in the American rap lyrics.

By observing a large number of lyrics, it is found that the values most lyrics convey are tightly centered round the moral norms and social values no matter they are combined with Chinese traditional literature or current reality, just like the above Example 1 and Example 2. The first example is to express sincere thanks to the family members who are unselfish and supportive, to friends who give a hand in time of need, and to his lover who gives him warmth. In the meantime, the whole rap conveys an optimistic attitude towards life through thanks for the growth from countless frustrations. The theme of the second example Jay Chou's Wounds of war is anti-war on the background of Vladivostok suffering from war, which is a subject of great concern. Instead of expressing passion for peace or criticizing the ferocity of the war, the whole rap just describes in detail the impact of the war on the local farmers and children, but it still has a great inspiring power. This rap shows Jay Chou's aversion to war and the sympathy for people who have been destroyed in the war, which is a tribute to the dead in the war and expresses a desire to appease the war.

Example 3:

Ruguo huatuozai shi congyangdoubeiyi zhi

(If Hua Tuo (master of traditional Chinese medicine) were reincarnated, the xenocentrism would be cured.)

Waibang laixuehan zi jifawomingzuyi shi

(Foreigners coming to learn Chinese inspire my national consciousness.)

Maqianzi juemingzi cangerzi haiyou lianzi

(Semen strychni, semen cassia, Fructus Xanthii and Semen Nelumbinis)

From Compendium of Materia Medica of Jay Chou [25]

This rap is a mix of hip-hop factors and Chinese style. The humorous hip-hop style makes the whole rap alive. The rap is intended to satirize the Chinese people who worship foreign things blindly. Jay Chou borrowed 16 herbal medicines in Compendium of Materia Medica---"Traditional Chinese Medicine Bible" to show the greatness of Chinese ancestors. Chinese people should be proud of China's excellent traditional medicine and cherish the traditional Chinese culture. This rap was performed in the 2009 Spring Festival gala, which is a typical song integrated traditional Chinese culture with hip-hop factors.

Example 4:

Zhiyao woxiangyaode douhuiyou

(I will get whatever I want.)

Danshi conglai doubuxuyao laoba mai

(But I never need my dad to buy for me.)

Genni butong, Xinganqingyuande dangge zhuchong

(Different from you, who are willing to be a moth.)

Woxiang kaozijideshuangshou zhuan

(I want to make a living by my own hands,)

Napa youduan shijian tebie qiong

(Even though I would be poor in a period of time.)

From Traps of Jony J [25]
Excerpts of this rap criticize the NEETs in society and satirize those young men who pursue leisure and lack of initiatives. Jony $\mathrm{J}$ encourages young people to be independent, self-reliant and hard-working to battle for their own life. The theme in this rap is consistent with moral norms and social values, which is full of positive power.

\subsubsection{Adaptation and Localization in Language Use of Rap}

In language use, dialect rap is another manifestation of localization. Since 2005, some local underground hip-hop groups have begun to rap in regional dialects, such as Shaanxi dialects rap, Beijing dialect rap, Chongqing dialect rap and so on. In dialect rap music, the rapper often uses a lot of regional slang dialect, which enables the rapper to construct a unique regional youth identity and consciousness as well as make the rap more humorous and impressive. Here are examples.

Example 5:

Wo jiushige chengduwawa zaichengdu zhege tata

(I'm from Chengdu and I live in Chengdu.)

Nishuowotujiutu ma wobengshaziheku ma

(There is no need being unhappy when people say I am rustic.)

Chengduren shuochengduhua shiduidesan

(Chengdu people should speak Chengdu dialect.)

Nizadeo naokemadesuo

(What is wrong with you? Your reply is a bit slow.)

From Beimen Hip Hop of Xie Di [25]

This rap is in Chengdu dialect, the typical Chengdu slang dialects have been marked with horizontal line, which create a humorous atmosphere. There seems to be a person from Chengdu who is crossing the area talks with you face to face. Other dialect raps resemble Chengdu dialect.

\subsubsection{Adaptation and Localization in the Dress-up of Rappers}

China covers a large territory and has many nationalities, hence a variety of regional economy and culture with great differences. The rappers from all over the nation form their own unique performance with regional characteristics. Taking the webcast program The Rap of China as an example, the program invites local rappers from all over the country to compete with each other, such as Ouyang Jing from Guangdong province, Gai and Bridge in Gosh Rap Group from Chongqing, etc. At the same time, the judges, Pan Weibo and $\mathrm{Wu}$ Yifan, have been growing in hip-hop culture atmosphere since childhood, so maybe they have deeper understanding of hip hop culture.

More importantly, the original hip-hop costumes and accessories were localized as well. Traditional Chinese patterns are printed on hip-hop costumes, or traditional Chinese garments are redesigned to become hip-hop costumes. For example, Wu Yifan, a judge in the Rap of China, wore redesigned Tang suit during the public performance, and some rappers wore the hip-hop costumes with Tai chi Yin and Yang design.

In general, with the development of hip-hop culture, Chinese hip-hop culture is no longer and will never be a 
simple copy of African-American or Korean hip-hop culture, especially in rap music. No matter in the language usage, lyrics form and content or the values, they have brought distinctive Chinese characteristics and reflected China's national conditions. Hip-hop culture witnesses localized adaptation and transformation through constantly absorbing the excellent Chinese culture so as to better integrate with Chinese culture while maintaining its own features like peace, confidence, realness, stamia.

\subsection{Summary and Discussion}

The involvement of commercial capital and the development of mass media provide a broad and convenient way for the dissemination and growth of hip-hop culture. The success of the entertainment program The Rap of China popularizes the localized hip-hop culture to the public, and it spreads a positive, healthy and keep-real value to its audience. In China, thanks to this program, hip-hop culture has gradually turned to more public from underground after continuous evolvement over the past 20 years. In general, hip-hop culture has initially realized cultural transformation in China.

However, cultural transformation is not the ultimate process of integration but only a link in dynamic integrating cycle. Chinese hip-hop cultural transformation is a historic process, which implements the reorganization through the conflicts and adjustments between hip-hop culture and Chinese culture so as to create a new culture. On the one hand, hip-hop culture is an internally creative transformation. In other words, when particular national or social culture, that is, African-American people's hip-hop culture, came to China, a new environment in new era, it would question and criticize itself and then takes continuous adjustments to achieve the internal creative transformation.

On the other hand, hip-hop culture transformation is also an externally critical reconstruction. Similar to African-American hip-hop content of lyrics, there were full of dirty slangs and negative values in Chinese rap at the beginning, such as the raps of MC Hotdog in Taiwan, which caused a great controversy in public; the negative events of the rapper PGone, etc. All these negative things make people question hip-hop culture and even directly regard it as rubbish, ringing the bell for the Chinese hip-hoppers. But later, in view of the provisions of National Ministry of Culture as well as the sense of social responsibility, domestic public rappers are more implicit in their creation, more healthy in word choice and more positive in values. But, one thing must be noticed that contradictions and conflicts never stop during the localization process of hip-hop culture. These two cultures are still adjusting and adapting to each other to create a new culture. Thus, it remains unclear as to how Chinese rap, or broadly speaking, hip-hop culture, evolves and innovates under the pressure of those scandals and in Chinese environment.

Today hip-hop culture is neither vulgar nor abusive, nor offensive. In foreign countries, rap has developed into a mature and multi-categorized music style, pursuing authenticity, freedom, relaxation and an expression of casual attitude towards life. In China, hip-hop culture is still fresh and in infancy, thus, the vulgar works are common phenomenon at the beginning, which can be regarded as a kind of cultural conflicts during the integration in a new environment. Therefore, the industry should think and localize the hip-hop culture alertly and reconsider how to commercialize it properly. More importantly, those who are engaged in and like the hip-hop culture should understand the real value of hip-hop culture deeply, and consider carefully how to integrate it with local culture and make the most of its positive influence.

In order to critically understand hip-hop culture and deal with cultural conflicts, people should take seriously hip-hop culture: the realization of the differences between Chinese traditional culture and African-American hip-hop culture would help young people objectively understand hip-hop culture and select the essence while discarding the dregs during acceptation. In addition, the Cultural Department is supposed to be strict and cautious to prevent the negative influence of hip-hop culture on the Chinese young people. Public figures as celebrities have to pay attention to their words and deeds as well as promote positive values; Commercial organizations like TV stations shall not immerse themselves in the audience rating and sponsorship fees regardless of the negative impact of certain culture. Like a proverb ever said that "when the fresh air comes in, the flies will also accompany it." Therefore, in a word, everyone should take a right attitude toward cultural integration -"take the essence and discard the dregs."

\section{Conclusions}

As a kind of "Grassroots Culture", hip-hop culture is originally an inner scream from people who are struggling with life rather than a form of entertainment when the people at the bottom of society are in their leisure time. After a long period of development and communication, Hip hop has become a mature sub-culture with a variety of classification for more than 40 years, advocating individuality and representing reality and pursuing innovation.

Hip-hop culture is positively accepted by the majority of teenagers after its landing on China's soil. Hip Hop is constantly mitigating and even discarding the violent and negative characteristics during the integration process through cultural dialogue, cultural adaptation and localization as well as transformation, combining with China's mainstream values. Taking advantage of hip-hop culture critically to inject new vitality into Chinese traditional culture will promote the further development of Chinese culture.

Explorative in essence, this study only adopted the qualitative research method with limited examples, and failed to analyze the influence from the audiences' perspective. Consequently, it is suggested that further research might concentrate on quantitative research or combination of both to obtain more persuasive evidence, and explore the reasons of popularity among young people from the perspective of 
adolescent psychology, so as to better develop and take the most of the advantages of hip-hop culture.

\section{Acknowledgements}

This research is sponsored by the Research Center for Business Culture and Philosophy of Culture, Guangdong University of Foreign Studies, Guangzhou, P. R. China.

\section{References}

[1] Berry, J. W. (1997). Immigration, acculturation, and adaptation Applied Psychology, 46 (1), 5-34.

[2] Mandaville, P. (2010) The Rise of Islamic Rap [EB/OL]. [Online] http://yaleglobalyale.edu/content/rise-islam

Available:

[3] Robertson, R. (1994) Globalisatio or glocalisation? [J]. The Journal of International Communication, 1: 1, 33-52.

[4] Philip, X., Halifu, O. and Awad I. (2007). Gazing the hood: Hip-Hop as tourism attraction [J]. Tourism Management, 452-460.

[5] Jaspal, S. \& Ethiraj, D. (2016). Cultural Intervention: Repositioning hip hop education in India [J]. Linguistics and Education, 55-64.

[6] Matt, G. (2014). Seen and not heard: The relationship of orthography, morphology, and phonology in loanword adaptation in the German hip hop community [J]. Discourse, Context \& Media, (3) 27-36.

[7] Athena, E. (2013). Greek hip hop: Local and translocal authentication in the restricted field of Production [J]. Poetics, 41 (1) 75-95.

[8] Ashish, P., Katherine, B., Biftu, M. and Andrea, V. (2017). Abortion and contemporary hip-hop: a thematic analysis of lyrics from 1990-2015 [J]. Contraception, 96 (1) 30-35.

[9] Mattew, W., Mario, A., Leah, H. et al (2018). The Hip Hop peer crowd: An opportunity for intervention to reduce tobacco use among at-risk youth [J]. Addictive Behaviors, 28-34.

[10] Katy, K. (2007) Cultural authenticity or cultural contamination: American musical influences on South African hip-hop culture [J]. Muziki, 4 (1).

[11] Barrett, C. (2012). Hip-hopping Across China: Intercultural Formulations of Local Identities [J]. Journal of Language, Identity \& amp; Education, 11 (4).
[12] Omoniyi, T. (2009). "So I choose to do am naija style". In Global linguistic flows: Hip-hop cultures, youth identities, and the politics of language. (A. 113-153). New York, NY: Routledge.

[13] Ping C. (2014). Chinese and American Hip-hop Culture and Educational Strategies from the Perspective of Youth Sub-culture [J]. Overseas English (09): 197-198+203.

[14] Ruiying, S. (2017). The Enlightenment of the Localization of Hip-Hop Culture from The Rap of China [J]. Southeast Communication. 2017 (11): 41-43.

[15] Hong, J. J. (2019). Design for Hip-hop Cheerleading Micro-lecture Teaching and Its Construction of Digital Platform under the Background of "Internet+" [J]. Journal of Changchun University, 29 (08): 106-110.

[16] Li, J. \& Guan, B. G. (2019). An Analysis of the Success or Failure of Double Hip-hop_-In 2018, the FLY Cheerleading Team at Serayshan Normal College is an Example [J]. Education Teaching Forum, (20) 242-243.

[17] Wang, L. and Zhu, X. L. (2018). The Analysis of the Youth Values behind the Phenomenon of "Chinese Hip Hop" [J]. Contemporary Youth Research, (02): 12-17.

[18] Gu, C. L. \& Qiu, L. Q. (2018). On the Value Guidance of Hip-hop Music to Young Students from the Perspective of Education [J]. Journal of Jiamusi Vocational Institute, (06): 203-204.

[19] Terry, F., Mark R. \& Chunmeizi S. (2019). Culture, Communication and merica $[\mathrm{M}]$. New York.

[20] Jin, L. (2014). Alternative Voice and Local Youth Identity in Chinese Local-Language Rap Music [J]. Positions: Asia Critique, 22 (1).

[21] Ke L. (2017). Analysis on the Youth sub-culture heat in The Rap of China [J]. Research on Transmission Competence, 1 (08): 84+109.

[22] Mesquita, B. \& De Leersnyder, J. \& Jasini, A. (2018). The cultural psychology of acculturation [M]. Guilford Press.

[23] Redfield, R., Linton, R. and Herskovits, M. (1936) Memorandum for Acculturation. American Anthropologist, 38, 149-152.

[24] Fuyi, Xing. (1991) Modern Chinese [M]. Higher Education.

[25] All lyrics are from online, available: www.xiaomi.com

[26] Kitawana, B. (2002). The Hip-hop Generation: Young Blacks and the Crisis in African American Culture [M]. New York: Basic Civitas. 